EGU2020-19406

https://doi.org/10.5194/egusphere-egu2020-19406

EGU General Assembly 2020

(c) Author(s) 2021. This work is distributed under

the Creative Commons Attribution 4.0 License.

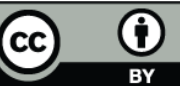

\title{
Flood variability in northern Spain during the last millennium recorded in lacustrine sedimentary archives
}

\author{
Juan Pablo Corella ${ }^{1}$, Bruno Wilhelm¹ , Gerardo Benito ${ }^{2}$, Anne-Catherine Favre ${ }^{1}$, and Blas L. Valero- \\ Garcés ${ }^{3}$ \\ ${ }^{1}$ Universite Grenoble Alpes, CNRS, IRD, IGE, 38000 Grenoble, France. \\ ${ }^{2}$ Geology Department, National Museum of Natural Sciences CSIC, Serrano 115bis, 28006 Madrid, Spain \\ ${ }^{3}$ Pyrenean Institute of Ecology CSIC, Zaragoza, Spain, Avda Montañana 1005, 50059 Zaragoza, Spain
}

Floods are among the most destructive natural disasters, and robust knowledge about their past, present and future trends is therefore crucial for the sustainable development of societies worldwide. Paleoflood deposits in lacustrine sedimentary sequences enable the continuous reconstruction of flood variability at centennial to millennial scale beyond instrumental hydrological datasets. FLOODARC MSCA project (2019-2021) aims to provide a more comprehensive understanding of the long-term flood variability in the Iberian Peninsula by investigating flood archives in several Spanish lake records. Preliminary results show a see-saw pattern in flood frequency variability during the Medieval Climate Anomaly and the Little Ice Age transition with more (less) flood events occurring during cold (warm) phases in Atlantic and Mediterranean areas respectively. These dissimilarities seem to be controlled by the hydroclimate variability at the regional scale as well as by historical land use changes in different areas of northern Spain. 